\title{
Backstepping/DTC control of a double star synchronous machine drive
}

\author{
D. BOUDANA, L. NEZLI, A.TLEMÇANI, M.O. MAHMOUDI, M. DJEMAI and M. TADJINE
}

\begin{abstract}
Direct torque control (DTC) allows for very high quality torque control without a need for current controllers tuning or using coordinate transformation. However, barge torque ripples arise as well as inconstant inverter switching frequency due to the hysteresis of comparators. This paper present a backstepping/DTC control based on the space vector modulation (SVPWM) for double star synchronous machine (DSSM) to reduce the torque, flux, current and speed pulsations during steady state. By the coordinate transformation the DSSM models are presented in view of control. Then a conventional DTC is developed to get a decoupled system and a PI controller is designed to control the speed. To improve the static and dynamic control performance of the DSSM, the speed controller is designed using a backstepping/DTC procedure in conjunction with SVPWM. Simulation results with the conventional DTC and proposed backstepping/DTC are presented and compared. Results show the effectiveness and the robustness of the approach proposed.
\end{abstract}

Key words: double star synchronous machine, direct torque control, backstepping/DTC, space vector modulation, robustness

\section{Introduction}

In the high power range, the synchronous machines are particularly attractive. For instance, the synchronous motor fed by current converter with intermediate DC-link are widely used in industrial adjustable speed drives. They operate in the same way as DC motors. However, the stator current present a large harmonic, and consequently, cause high torque oscillations [1],[2].

With the development of high power semi conductor devices, synchronous machine are supplied by voltage source inverter. But the limitations on the gate-turn-off lead to the high current and torque ripple. To overcome this problem, synchronous machine is fed by multilevel inverter. Another way is application of the power segmentation on both inverter and machine. The most common structure uses double star synchronous machine whose winding are spatially phase shifted by 30 electrical degrees, supplied with source

D. Boudana, L. Nezli, A.Tlemçani, M.O. Mahmoudi and M. Tadjine are with LCP, ENP, 10 av. Pasteur, Hassen Badi, 16200 El Harrach, Alger, Algeria. M. Djemai is with ECS, ENSEA, 6 av. du Ponceau, 95014 Cergy-Pontoise Cedex, France. Corresponding author is A.Tlemçani, e-mail: h_tlemcani@yahoo.fr

Received 14.04.2008. 
voltage inverters [3],[4]. Double star synchronous machine possesses several advantages over conventional three phase machine. This includes: increasing the inverter output power, reducing the amplitude of torque ripple, lowering the dc link current harmonics and improving the reliability, enabling of the the motor start and run even the loss of one or more phases [5].

Several methods have been proposed for the control of DSSM [6],[7],[8]. Complexity and parameters sensitivity are the most important disadvantages of these methods. An alternative solution is the use of direct torque control strategies [9]. The principle of conventional DTC is to select stator voltage vectors, according to the differences between the stator flux linkage and torque and their references, to keep stator flux and torque within the limits of two hysteresis bands. DTC allows for decoupling of the control of flux and torque without a need of coordinate transformation, PWM pulse generation and current regulation [10],[11]. The DTC has many advantages such as lower machine parameter dependence, fast torque response, elimination of $\mathrm{d}-\mathrm{q}$ axes and rotor position sensor. However, the presence of hysteresis of the controllers leads to significant torque, flux and current pulsations and non-constant switching frequency operation. Otherwise, backstepping control is a newly developed technique for the control of uncertain nonlinear systems, particularly systems which do not satisfy matching conditions. The most appealing point is to use the virtual control variable to make the original high-order system simple, thus the final control outputs can be derived step by step through suitable Lyaponov functions [12]. The application of this new technique in association with the DTC gives a new structure which allows for reducing the torque ripple and fixing the switching frequency.

In this paper, we propose a novel and simple backstepping/DTC strategy for double star synchronous machine to reduce the flux and torque ripple, and also to keep fixed switching frequency. The objective of the proposed control strategy is to replace the hysteresis controllers used in the conventional DTC by a backstepping/DTC strategy control in conjunction with SVPWM techniques. The proposed approach is verified and compared with the conventional DTC by simulation experiments.

\section{Formulation of the problem}

The stator voltage equation for DSSM is given by:

$$
\left[v_{s}\right]=\left[R_{s}\right]\left[i_{s}\right]+\frac{d}{d t}\left(\left[L_{s s}\right]\left[i_{s}\right]+\left[M_{s r}\right] i_{f}\right)
$$

with

$$
\begin{aligned}
& {\left[v_{s}\right]=\left[\begin{array}{llllll}
v_{a 1} & v_{a 2} & v_{b 1} & v_{b 2} & v_{c 1} & v_{c 2}
\end{array}\right]^{T}} \\
& {\left[i_{s}\right]=\left[\begin{array}{llllll}
i_{a 1} & i_{a 2} & i_{b 1} & i_{b 2} & i_{c 1} & i_{c 2}
\end{array}\right]^{T} \text {. }}
\end{aligned}
$$


The original six dimensional system of the machine can be expressed in the rotor flux reference frame d-q plan as follows:

$$
\left\{\begin{array}{l}
v_{d}=R_{s} i_{d}+L_{d} \frac{d i_{d}}{d t}-w L_{d} i_{q} \\
v_{q}=R_{s} i_{q}+L_{d} \frac{d i_{q}}{d t}+w L_{d} i_{d}+w \phi_{r} .
\end{array}\right.
$$

The electromagnetic torque equation is:

$$
T_{e}=P\left(\phi_{d} i_{q}-\phi_{q} i_{d}\right)
$$

with

$$
\phi_{r}=M_{d} i_{f}
$$

and rotating speed of rotor flux linkage

$$
\phi_{d}=L_{d} i_{d}+\phi_{r}, \quad \phi_{q}=L_{q} i_{q}
$$

In order to control directly and independently the flux and the torque the model of the DSSM is expressed in the stator flux reference frame by using the transformation, which transforms variable in the rotor flux reference frame $(d-q)$ to the stator flux reference frame x-y sa follows (Fig. 1):

$$
\left[\begin{array}{cc}
\cos \delta & \sin \delta \\
-\sin \delta & \cos \delta
\end{array}\right]
$$

The electrical equations for the DSSM in x-y reference frame are as follows [15]:

$$
\left\{\begin{array}{l}
v_{x}=R_{s} i_{x}-w_{s} L_{d} i_{y}+L_{d} \frac{d i_{x}}{d t}+w \phi_{r} \sin \delta \\
v_{y}=R_{s} i_{y}+w_{s} L_{d} i_{x}+L_{d} \frac{d i_{y}}{d t}+w \phi_{r} \cos \delta
\end{array}\right.
$$

where: $w_{s}$ is the rotating speed of stator flux linkage and $\delta$ is the angle between rotor and stator flux linkage.

The fluxes and the torque are given by:

$$
\left\{\begin{array}{l}
\phi_{x}=\phi_{s}=L_{d} i_{x}+\phi_{r} \cos \delta \\
\phi_{y}=0=L_{d} i_{y}-\phi_{r} \sin \delta \\
T_{e}=P \phi_{s} i_{y} .
\end{array}\right.
$$

From (8) and (9) the model for the DSSM can be written as follows:

$$
\left\{\begin{array}{l}
\frac{d i_{y}}{d t}=f_{1}+b v_{y} \\
\frac{d \phi_{s}}{d t}=f_{2}+v_{x} \\
j \frac{d w}{d t}=T_{e}-T_{r}
\end{array}\right.
$$




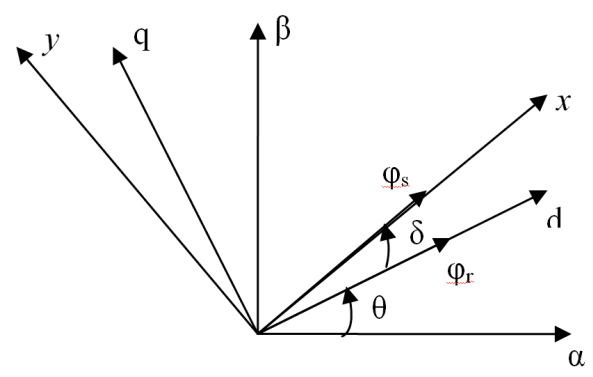

Figure 1. The stator and rotor flux linkages in different reference frames.

where

$$
\left\{\begin{array}{l}
f_{1}=-\frac{1}{L_{d}}\left(R_{s} i_{y}+w_{s} \phi_{s}+\left(w_{s}-w\right) \phi_{r} \cos \delta\right) \\
f_{2}=-\frac{R_{s}}{L_{d}}\left(\phi_{s}-\phi_{r} \cos \delta\right) \\
b=\frac{1}{L_{d}} .
\end{array}\right.
$$

The considered DSSM problem is to get a decoupling system between flux and torque and to track a desired reference for the speed. To do this, the control law is designed using the backstepping methodology together with a DTC structure. The equation of dynamics (10) allows for the following conclusions:

1. The speed can be controlled using the torque.

2. The flux can be controlled directly using the real control signal $v_{x}$.

3. The torque can be controlled directly using the real control signal $v_{y}$.

\section{Direct Torque control of DSSM}

The instantaneous electromagnet torque $T_{e}$ of DSSM is expressed as:

$$
T_{e}=\frac{1}{L_{d}} P \phi_{s} \phi_{r} \sin (\delta)
$$

It can be seen that $T_{e}$ can be controlled by keeping the amplitude of the stator flux linkage constant and controlling the angle between the stator and rotor flux linkage. In DTC control, the stator flux linkage and the torque are directly controlled, using torque hysteresis controller and flux hysteresis controller to set the output voltage vector of inverter (Fig. 2). 


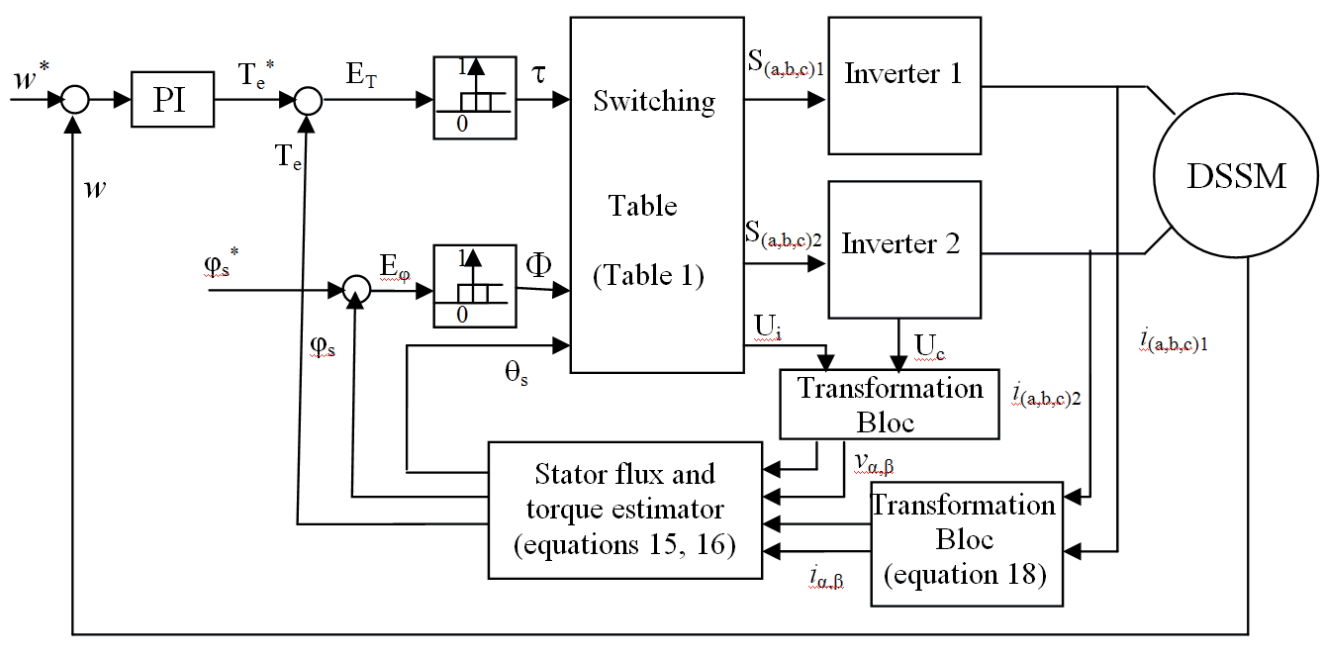

Figure 2. Direct torque control scheme for DSSM.

The principle of DTC control can be expressed on the base of space vector notation. The space vectors of the voltage, current and flux of the DSSM are defined as follows:

$$
\left\{\begin{array}{l}
\bar{v}_{s}=\sqrt{\frac{2}{3}}\left(v_{a 1}+v_{b 1} e^{j \frac{2 \pi}{3}}+v_{c 1} e^{j \frac{4 \pi}{3}}+v_{a 2} e^{j \gamma}+v_{b 2} e^{j\left(\frac{2 \pi}{3}+\gamma\right)}+v_{c 2} e^{j\left(\frac{4 \pi}{3}+\gamma\right)}\right) \\
\bar{i}_{s}=\sqrt{\frac{2}{3}}\left(i_{a 1}+i_{b 1} e^{j \frac{2 \pi}{3}}+i_{c 1} e^{j \frac{4 \pi}{3}}+i_{a 2} e^{j \gamma}+i_{b 2} e^{j\left(\frac{2 \pi}{3}+\gamma\right)}+i_{c 2} e^{j\left(\frac{4 \pi}{3}+\gamma\right)}\right) \\
\bar{\phi}_{s}=\sqrt{\frac{2}{3}}\left(\phi_{a 1}+\phi_{b 1} e^{j \frac{2 \pi}{3}}+\phi_{c 1} e^{j \frac{4 \pi}{3}}+\phi_{a 2} e^{j \gamma}+\phi_{b 2} e^{j\left(\frac{2 \pi}{3}+\gamma\right)}+\phi_{c 2} e^{j\left(\frac{4 \pi}{3}+\gamma\right)}\right) .
\end{array}\right.
$$

Neglecting the stator resistance, the relation between the stator flux linkage vector and the voltage vector of DSSM can be approximated by:

$$
\bar{\phi}_{s}\left(T_{s}\right) \approx \bar{v}_{s} T_{s}+\bar{\phi}_{s}(0)
$$

where $T_{s}$ is the sampling period.

Equation (14) shows that the end of the stator flux linkage vector $\phi_{s}$ moves along the direction of voltage vector applied. To select the proper voltage vectors which keep the amplitude of $\phi_{s}$ constant and control the direction of the rotation of $\phi_{s}$ we use a predefined switching table [16],[17]. For the conventional DTC the stator flux linkage and the torque are estimated with as:

$$
\left\{\begin{array}{l}
\phi_{\alpha}(t)=\int_{0}^{t}\left(v_{\alpha}-R_{s} i_{\alpha}\right) d \tau+\phi_{\alpha}(0) \\
\phi_{\beta}(t)=\int_{0}^{t}\left(v_{\beta}-R_{s} i_{\beta}\right) d \tau+\phi_{\beta}(0) \\
\phi_{s}=\sqrt{\phi_{\alpha}^{2}+\phi_{\beta}^{2}} \\
\operatorname{tg} \theta_{s}=\frac{\phi_{\beta}(t)}{\phi_{\alpha}(t)}
\end{array}\right.
$$




$$
T_{e}=P\left(\phi_{\alpha} i_{\beta}-\phi_{\beta} i_{\alpha}\right)
$$

where

$$
\left[\begin{array}{llllll}
F_{\alpha} & F_{\beta} & F_{z 1} & F_{z 2} & F_{z 3} & F_{z 4}
\end{array}\right]^{T}=\left[T_{s}\right]\left[F_{s}\right]
$$

$F_{S}$ is voltage, courant or flux and

$$
\left[T_{s}\right]=\frac{1}{\sqrt{3}}\left[\begin{array}{cccccc}
\cos (0) & \cos (\gamma) & \cos \left(\frac{2 \pi}{3}\right) & \cos \left(\frac{2 \pi}{3}+\gamma\right) & \cos \left(\frac{4 \pi}{3}\right) & \cos \left(\frac{4 \pi}{3}+\gamma\right) \\
\sin (0) & \sin (\gamma) & \sin \left(\frac{2 \pi}{3}\right) & \sin \left(\frac{2 \pi}{3}+\gamma\right) & \sin \left(\frac{4 \pi}{3}\right) & \sin \left(\frac{4 \pi}{3}+\gamma\right) \\
\cos (0) & \cos (\pi-\gamma) & \cos \left(\frac{4 \pi}{3}\right) & \cos \left(\frac{\pi}{3}-\gamma\right) & \cos \left(\frac{2 \pi}{3}\right) & \cos \left(\frac{5 \pi}{3}-\gamma\right) \\
\sin (0) & \sin (\pi-\gamma) & \sin \left(\frac{4 \pi}{3}\right) & \sin \left(\frac{\pi}{3}-\gamma\right) & \sin \left(\frac{2 \pi}{3}\right) & \sin \left(\frac{5 \pi}{3}-\gamma\right) \\
1 & 0 & 1 & 0 & 1 & 0 \\
0 & 1 & 0 & 1 & 0 & 1
\end{array}\right]
$$

\section{Selection of voltage vectors}

The DSSM is supplied with two VSIs. Each inverter can be controlled independently. However, if we consider the two inverters as a six-phase voltage source inverter we obtain a total of 64 switching modes. By using the transformation matrix (18) the 64 voltage vectors corresponding to the switching modes are projected on three planes. From 64 vectors there are only 12 voltage vectors that offer a maximum voltage on the $\alpha-\beta$ plane and keep the harmonics on the $Z_{1} Z_{2}$ plane at a minimum [5],[14],[18].

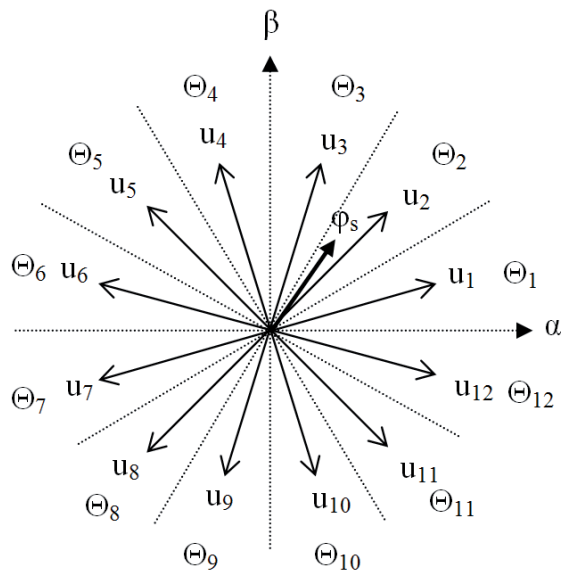

Figure 3. The chosen inverter voltage vectors projected on $\alpha-\beta$ plane.

The voltage vector plane is divided into twelve sectors so that each voltage vector divides each region into two equal parts as shown in Fig. 3. In each sector, four of the 
Table 4. The switching states for inverters

\begin{tabular}{|c|c|c|c|c|c|c|c|c|c|c|c|c|c|}
\hline \hline$\Phi$ & $\tau \backslash \Theta$ & $\Theta_{1}$ & $\Theta_{2}$ & $\Theta_{3}$ & $\Theta_{4}$ & $\Theta_{5}$ & $\Theta_{6}$ & $\Theta_{7}$ & $\Theta_{8}$ & $\Theta_{9}$ & $\Theta_{10}$ & $\Theta_{11}$ & $\Theta_{12}$ \\
\hline \hline \multirow{2}{*}{$\Phi=1$} & $\tau=1$ & $u_{3}$ & $u_{4}$ & $u_{5}$ & $u_{6}$ & $u_{7}$ & $u_{8}$ & $u_{9}$ & $u_{10}$ & $u_{11}$ & $u_{12}$ & $u_{1}$ & $u_{2}$ \\
\cline { 2 - 14 } & $\tau=0$ & $u_{11}$ & $u_{12}$ & $u_{1}$ & $u_{2}$ & $u_{3}$ & $u_{4}$ & $u_{5}$ & $u_{6}$ & $u_{7}$ & $u_{8}$ & $u_{9}$ & $u_{10}$ \\
\hline \multirow{2}{*}{$\Phi=0$} & $\tau=1$ & $u_{5}$ & $u_{6}$ & $u_{7}$ & $u_{8}$ & $u_{9}$ & $u_{10}$ & $u_{11}$ & $u_{12}$ & $u_{1}$ & $u_{2}$ & $u_{3}$ & $u_{4}$ \\
\cline { 2 - 12 } & $\tau=0$ & $u_{9}$ & $u_{10}$ & $u_{11}$ & $u_{12}$ & $u_{1}$ & $u_{2}$ & $u_{3}$ & $u_{4}$ & $u_{5}$ & $u_{6}$ & $u_{7}$ & $u_{8}$ \\
\hline \hline
\end{tabular}

twelve voltage vectors may be used. The switching table used in this work is indicated in Tab. 1. The output of the flux hysteresis comparator is denoted as $\Phi$, the output of the torque hysteresis comparator is denoted as $\tau$. The flux hysteresis comparator is a two valued comparator. $\Phi=1$ means that the actual value of the amplitude of the flux linkage is below the reference value and $\Phi=0$ means that the actual value is above the reference value. The same is true for the torque.

\section{Proposed backstepping/DTC for DSSM}

The proposed backstepping/DTC control retains the advantages of the conventional DTC. In fact, instead of the hysteresis controllers a backstepping/DTC control is used for the speed of the DSSM to track the reference speed and get decoupling between stator flux linkage and torque (Fig. 4).

Let $e_{w}=w-w^{*}, e_{\phi}=\phi-\phi^{*}$ and $e_{T}=T-T^{*}$. The following result can be established.

Proposition Consider the DSSM plant model (10). Let the backstepping/DTC controllers be:

$$
\left\{\begin{array}{l}
v_{x}=-f_{2}+\dot{\phi}_{s}^{*}-k_{2}\left(\phi_{s}-\phi_{s}^{*}\right) \\
v_{y}=\frac{-1}{p b \phi_{s}}\left[p \phi_{s} f_{1}+k_{1}\left(T_{e}-T_{e}^{*}\right)+\left(w-w^{*}\right)+p \dot{\phi}_{s} i_{y}-\dot{T}_{e}^{*}\right] \\
T_{e}^{*}=j \dot{w}^{*}-k_{3}\left(w-w^{*}\right)-k_{4} \operatorname{sign}\left(w-w^{*}\right)
\end{array}\right.
$$

where $k_{1}, k_{2}, k_{3}>0$ and $k_{4}>\max \left(T_{r}\right), \phi_{s} \neq 0$. Then $e_{w}, e_{\phi}$ and $e_{T}$ are asymptotically stable.

Proof The proof is based on two steps using the backstepping/DTC approach. 


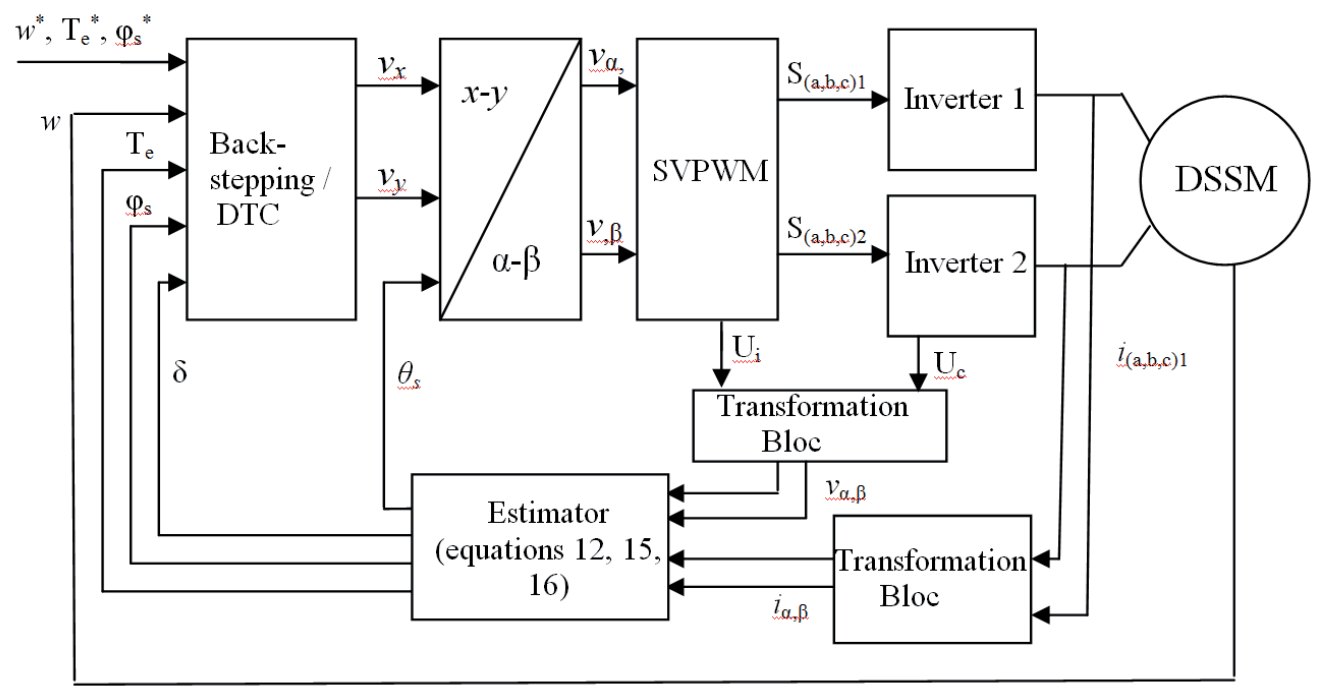

Figure 4. Proposed Backstepping /DTC scheme for DSSM.

\section{Step 1}

Consider the following Lyapunov function related to the speed dynamic defined in (10):

$$
\left\{V_{1}=\frac{1}{2} j\left(w-w^{*}\right)^{2}>0\right.
$$

This function is globally positive definite over the whole state space. Its derivative is given by:

$$
\dot{V}_{1}=j\left(w-w^{*}\right)\left(\dot{w}-\dot{w}^{*}\right)=\left(w-w^{*}\right)\left(T_{e}-T_{r}-j \dot{w}^{*}\right) .
$$

If it is supposed that $T_{e} \rightarrow T_{e}^{*}$, we obtain

$$
\dot{V}_{1}=-k_{3}\left(w-w^{*}\right)^{2}-\left(w-w^{*}\right)\left[-k_{4} \operatorname{sign}\left(w-w^{*}\right)-T_{r}\right]
$$

The term: $\left(w-w^{*}\right)\left[-k_{4} \operatorname{sign}\left(w-w^{*}\right)-T_{r}\right]<0 ; \forall\left(w-w^{*}\right)$ and $\forall T_{r}$ than

$$
\dot{V}_{1}<-k_{3}\left(w-w^{*}\right)^{2}<0 .
$$

This means that $w$ converge exponentially to $w^{*}$. Hence if $T_{e}$ is forced to take the desired value $T_{e}^{*}$, the speed tracking error tends to zero.

\section{Step 2}

The objective of this step is to establish the control voltage $v_{x}$ that impose $\phi_{s}$ to acquire the desired value $\phi_{s}^{*}$ and the control voltage $v_{y}$ that impose $T_{e}$ to acquire the desired value $T_{e}^{*}$. Consider the augmented Lyapunov function:

$$
V_{2}=V_{1}+\frac{1}{2}\left(\phi-\phi^{*}\right)^{2}+\frac{1}{2}\left(T_{e}-T_{e}^{*}\right)^{2}>0 .
$$


Its time derivative is expressed by:

$$
\dot{V}_{2}=\dot{V}_{1}+\left(\phi_{s}-\phi_{s}^{*}\right)\left(\dot{\phi}_{s}-\dot{\phi}_{s}^{*}\right)+\left(T_{e}-T_{e}^{*}\right)\left(\dot{T}_{e}-\dot{T}_{e}^{*}\right) .
$$

Recall that:

$$
\dot{V}_{1}=\left(w-w^{*}\right)\left(T_{e}-T_{r}-j \dot{w}^{*}\right)=\left(w-w^{*}\right)\left(T_{e}-T_{e}^{*}\right)+\left(w-w^{*}\right)\left(T_{e}^{*}-T_{r}-j \dot{w}^{*}\right)
$$

Replacing $T_{e}^{*}$ by its value from (19), we obtain:

$$
\left(w-w^{*}\right)\left(T_{e}-T_{e}^{*}\right)+\left(w-w^{*}\right)\left(T_{e}^{*}-T_{r}-j \dot{w}^{*}\right) \leqslant\left(w-w^{*}\right)\left(T_{e}-T_{e}^{*}\right)-k_{3}\left(w-w^{*}\right)^{2} .
$$

The derivative of the Lyapunov function (25) becomes:

$$
\dot{V}_{2} \leqslant\left(w-w^{*}\right)\left(T_{e}-T_{e}^{*}\right)-k_{3}\left(w-w^{*}\right)^{2}+\left(\phi_{s}-\phi_{s}^{*}\right)\left(\dot{\phi}_{s}-\dot{\phi}_{s}^{*}\right)+\left(T_{e}-T_{e}^{*}\right)\left(\dot{T}_{e}-\dot{T}_{e}^{*}\right) .
$$

The torque and the flux are given by (11) and their derivatives are:

$$
\left\{\begin{array}{l}
\dot{T}_{e}=p \dot{\phi}_{s} i_{Y}+p \phi_{s} \dot{i}_{y} \\
\dot{i}_{y}=f_{1}+b v_{y} \\
\dot{\phi}_{s}=f_{2}+v_{x} .
\end{array}\right.
$$

Replacing the control low (19) in (29), equation (28) becomes:

$$
\dot{V}_{2} \leqslant-k_{3}\left(w-w^{*}\right)^{2}-k_{2}\left(\phi_{s}-\phi_{s}^{*}\right)^{2}-k_{1}\left(T_{e}-T_{e}^{*}\right)^{2}<0 .
$$

Hence using the Lyapunov theorem, we conclude that:

$$
\left\{\begin{array}{l}
\lim _{t \rightarrow+\infty}\left(w-w^{*}\right)=0 \\
\lim _{t \rightarrow+\infty}\left(\phi_{s}-\phi_{s}^{*}\right)=0 \\
\lim _{t \rightarrow+\infty}\left(T_{e}-T_{e}^{*}\right)=0 .
\end{array}\right.
$$

That is, the tracking errors are asymptotically stable.

\section{Space vector PWM}

The presence of hysteresis controllers in the conventional DTC strategy produces varying switching frequency during operation of the inverters. But the space vector PWM control allows for operating in the constant switching frequency. The objective of SVPWM control is to approximate the reference voltage vector instantaneously by combination of switching states corresponding to the basic space vectors. During each sampling period $T_{s}$, a set of five voltage vectors are chosen to synthesize the $\alpha-\beta$ voltages 
vectors and to maintain the average volt-seconds $Z_{1} Z_{2}$ planes to be zero. The SVPWM strategy is accomplished by the following equations [5],[14]:

$$
\begin{aligned}
{\left[\begin{array}{c}
T_{n-2} \\
T_{n-1} \\
T_{n} \\
T_{n+1}
\end{array}\right] } & =\left[\begin{array}{cccc}
v_{\alpha}^{n-2} & v_{\alpha}^{n-1} & v_{\alpha}^{n} & v_{\alpha}^{n+1} \\
v_{\beta}^{n-2} & v_{\beta}^{n-1} & v_{\beta}^{n} & v_{\beta}^{n+1} \\
v_{z 1}^{n-2} & v_{z 1}^{n-1} & v_{z 1}^{n} & v_{z 1}^{n+1} \\
v_{z 2}^{n-2} & v_{z 2}^{n-1} & v_{z 2}^{n} & v_{z 2}^{n+1}
\end{array}\right]^{-1}\left[\begin{array}{c}
v_{\alpha}^{*} T_{s} \\
v_{\beta}^{*} T_{s} \\
0 \\
0
\end{array}\right] \\
T_{0} & =T_{s}-\left(T_{n+1}+T_{n}+T_{n-1}+T_{n-2}\right)
\end{aligned}
$$

where $v_{x}^{k}$ is the projection of the $k$ th voltage vector on the $x$ axis and $T_{k}$ is the dwell time of that vector during time interval $T_{S}$. The quantities $v_{\alpha}^{*}$ and $v_{\beta}^{*}$ are the $\alpha-\beta$ plane reference voltages (Fig. 5). At any PWM period, the applied sequence of adjacent vectors $v_{n-2}, v_{n-1}, v_{n}, v_{n+1}$ and the zero vector $v_{0}$ are $v_{0}-v_{n-2}-v_{n-1}-v_{n}-v_{n+1}-v_{0}-v_{n+1}-$ $v_{n}-v_{n-1}-v_{n-2}-v_{0}$ and the respective durations are:

$$
\frac{T_{0}}{4}, \frac{T_{n-2}}{2}, \frac{T_{n-1}}{2}, \frac{T_{n}}{2}, \frac{T_{n+1}}{2}, \frac{T_{0}}{2}, \frac{T_{n+1}}{2}, \frac{T_{n}}{2}, \frac{T_{n-1}}{2}, \frac{T_{n-2}}{2}, \frac{T_{0}}{4} .
$$

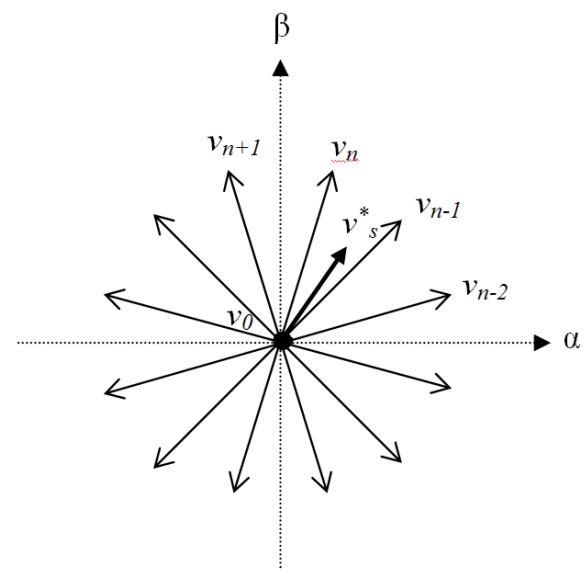

Figure 5. The applied sequence of adjacent vectors.

\section{Comparative study}

In this section, we aim to compare our proposed scheme to the conventional DTC for DSSM. We consider three situations: 


\section{Situation 1: Step change in torque.}

For backstepping/DTC and conventional DTC for DSSM we have imposed a reference torque $10[\mathrm{Nm}]$ at time $0.2[\mathrm{~ms}]$. Fig. 7 and 8 present obtained results. We can see, that both control approaches ensure good flux linkage and torque tracking. Furthermore, both methods of control allow for exact decoupling between stator flux linkage and torque. However, the backstepping/DTC for DSSM decreases considerably the torque ripple and provides faster torque response.

\section{Situation 2: Speed tracking.}

To test the speed tracking we have simulated both control approaches:

a. Fig. 9 and 10: speed step response of amplitude $100[\mathrm{rd} / \mathrm{s}]$ with load torque $\operatorname{Tr}=$ $8[\mathrm{Nm}]$ applied at time $t=1[\mathrm{sec}]$.

b. Fig. 11 and 12: speed square step response of amplitude $100[\mathrm{rd} / \mathrm{s}]$ with the machine not loaded.

In both control approaches a torque limiter was introduced in order to limit the produced torque to the value $10[\mathrm{Nm}]$. It can be observed, that with both, PI speed controller and backstepping/DTC speed controller, the speed track its reference and the rejection of disturbance is immediate.

\section{Situation 2: Stator resistance variation.}

For both DTC control schemes we have simulated variation of stator resistance as shown in Fig. 15. The obtained results, shown in Fig. 13 and 14, show that the torque and flux are oscillating when stator resistance is increased. Thus incorrect resistance stator can cause instability. To overcome this problem we used the stator resistance estimator shown in Fig. 6. The error in the stator current is used as an input to the PI estimator. The output of the PI estimator is continuously added to the previously estimated stator resistance.

Fig. 15,16 and 17 show the actual and estimated stator resistance and their error, respectively. In Fig. 18 and 19 we have inserted the estimated stator resistance in control scheme. The obtained results are very satisfactory.

Table 2 summarizes the results of the comparative study. From this results one can can conclude, that for the DSSM, the backstepping/DTC is significantly better than the conventional DTC. 
Table 5. Comparative study between backstepping/DTC and conventional DTC for DSSM.

\begin{tabular}{|c|c|c|c|c|}
\hline & $\begin{array}{l}\text { Torque } \\
\text { ripple }\end{array}$ & $\begin{array}{c}\text { Response } \\
\text { time }\end{array}$ & $\begin{array}{c}\text { Speed } \\
\text { response }\end{array}$ & $\begin{array}{c}\text { Stator } \\
\text { resistance } \\
\text { variation }\end{array}$ \\
\hline Backstepping/DTC & $1.3 \%$ & $5[\mathrm{~ms}]$ & $\begin{array}{l}\text { - Good tracking } \\
\text { - Good decoupling } \\
\text { - Rejection of disturbance }\end{array}$ & Unstable \\
\hline Conventional DTC & $2.4 \%$ & 10 [ms] & $\begin{array}{l}\text { - Good tracking } \\
\text { - Exact decoupling } \\
\text { - Rejection of disturbance }\end{array}$ & Unstable \\
\hline
\end{tabular}

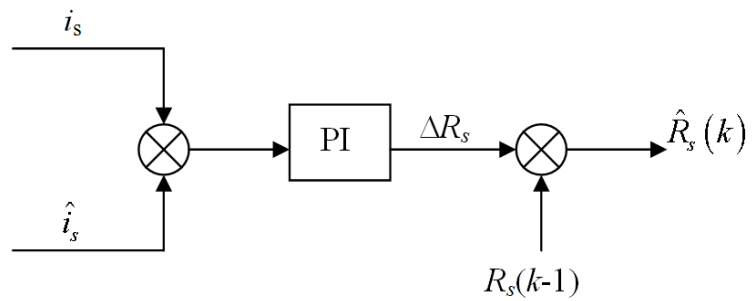

Figure 6. Block diagram of the stator resistance estimator ( $\hat{i}_{s}$ is the estimated stator current).

\section{Conclusion}

In this paper, backstepping/DTC method for DSSM is presented based on voltage space vector modulation. The proposed method reduces the torque/flux ripples and preserves the advantages of the conventional DTC. The use of SVPWM to assure the DSSM voltage demand in the proposed method allows for operating at the constant and controllable switching frequency. In conventional DTC a single voltage vector is applied during sampling time. In backstepping/DTC-SVPWM a sequence of six vectors is applied during the same time. Simulations results verify the effectiveness of the backstepping/DTCSVPWM control both in dynamic and static performances. 

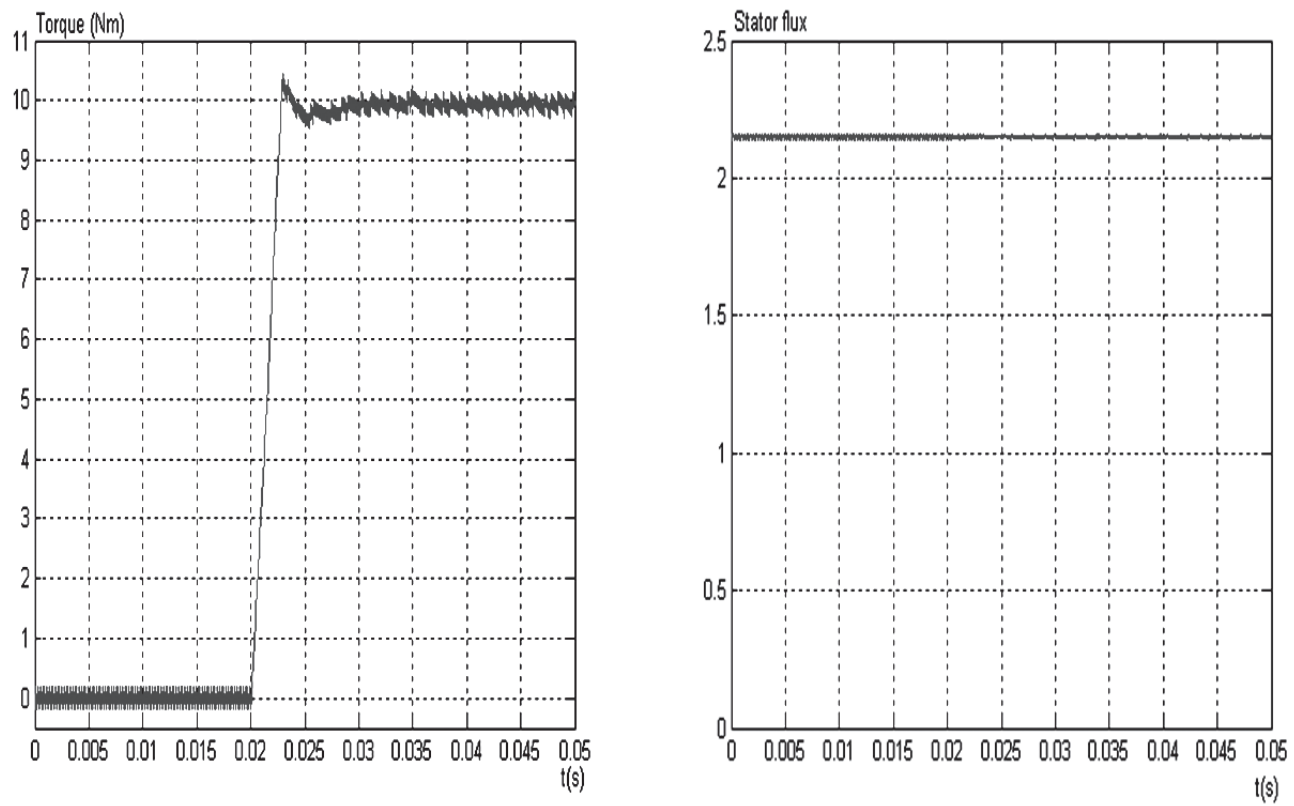

Figure 7. Performance of conventional DSSM DTC for situation 1.
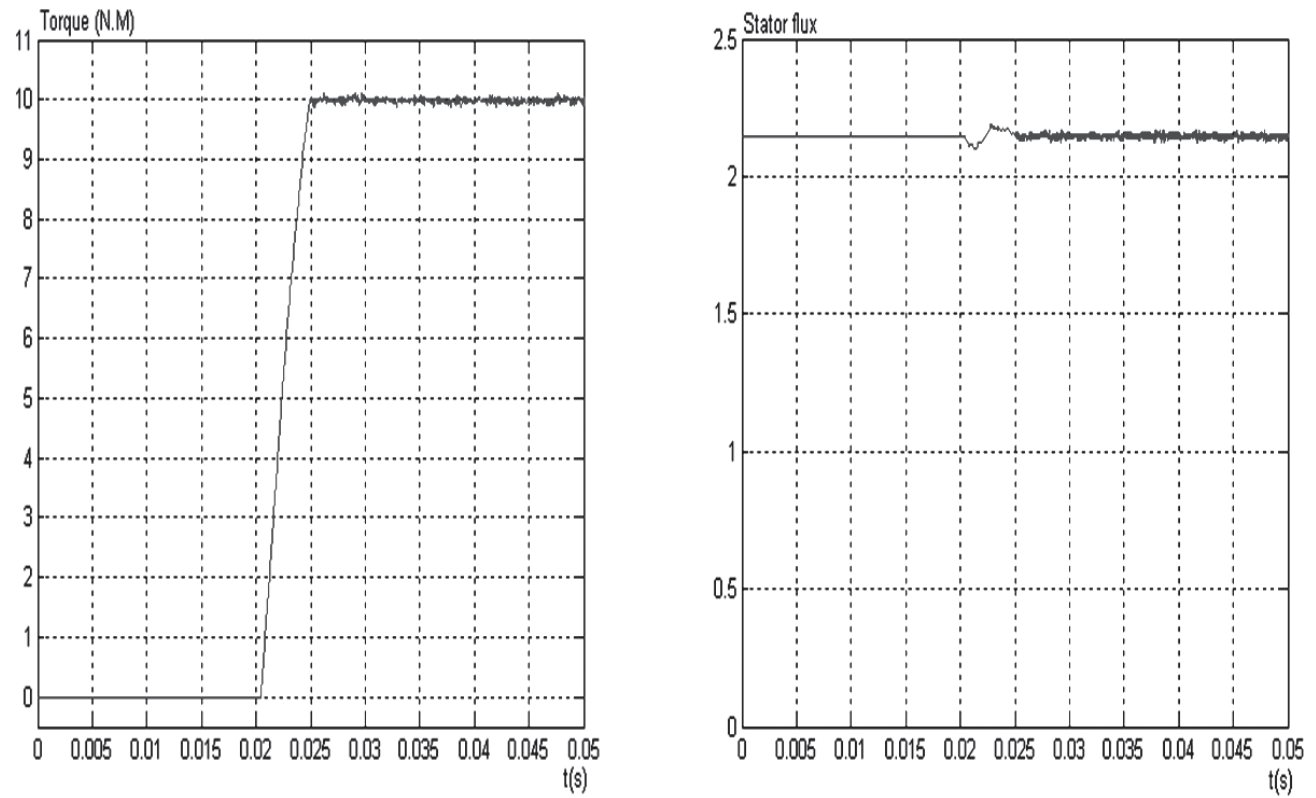

Figure 8. Performance of backstepping/DTC control of DSSM for situation 1. 

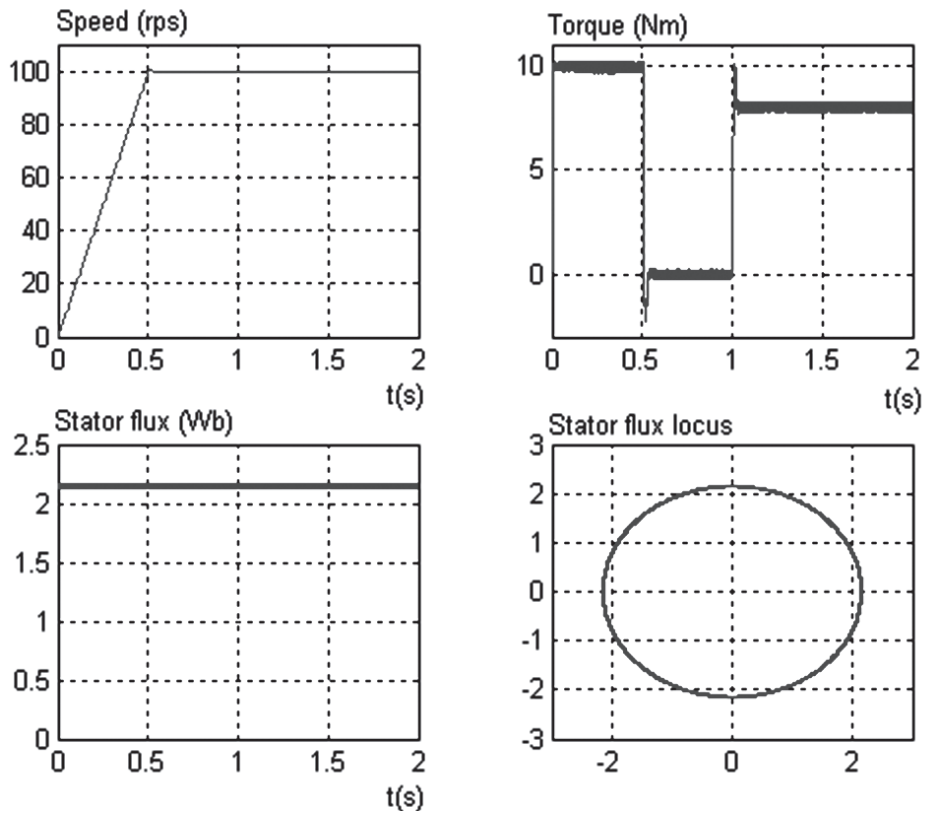

Figure 9. Performance of conventional DSSM DTC for situation 2-a.
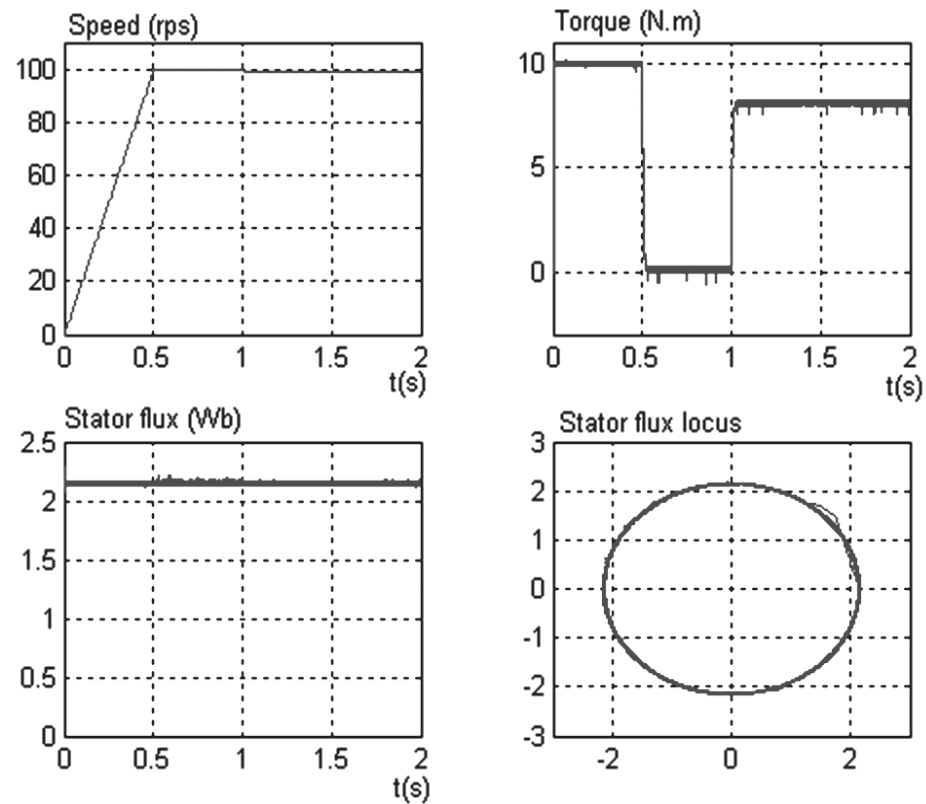

Figure 10. Performance of backstepping/DTC control of DSSM for situation 2-a. 

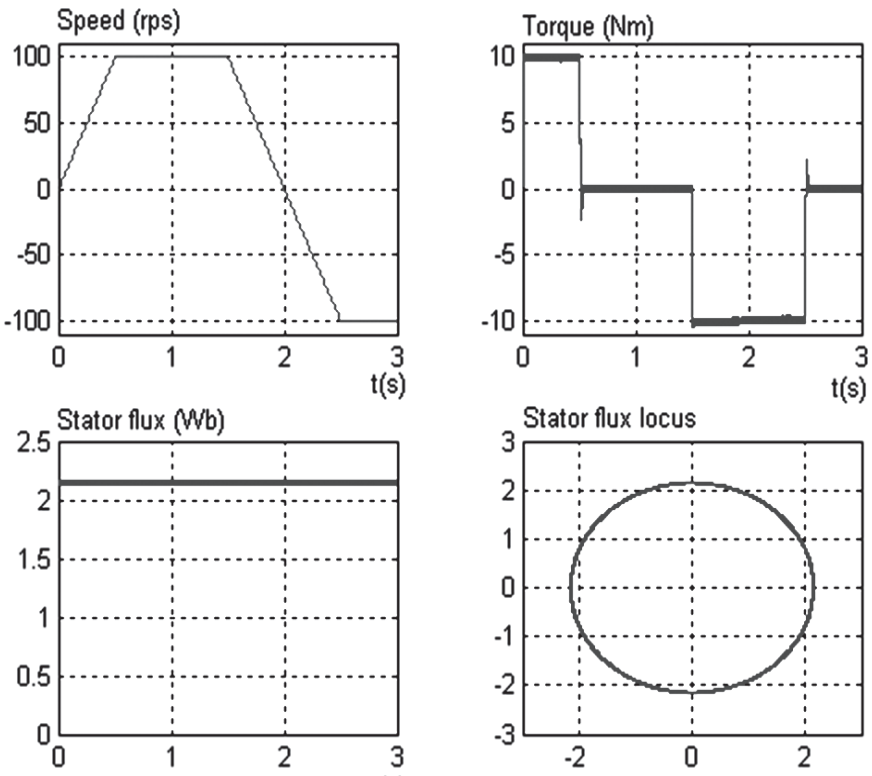

$t(s)$

Figure 11. Performance of conventional DSSM DTC for situation 2-b.
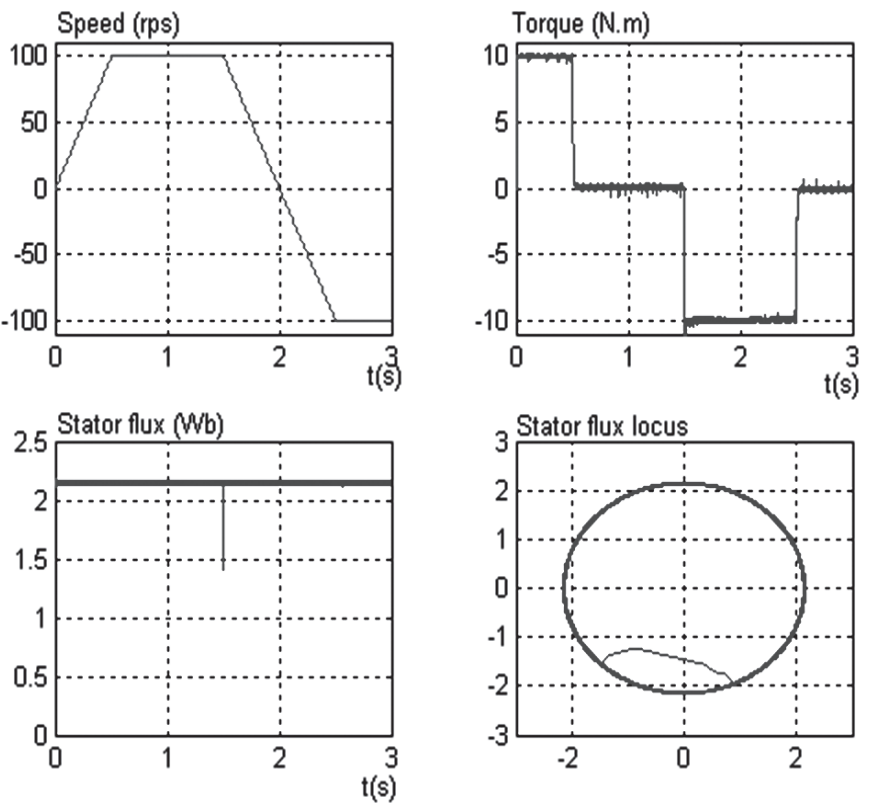

Figure 12. Performance of backstepping/DTC control of DSSM for situation 2-b. 

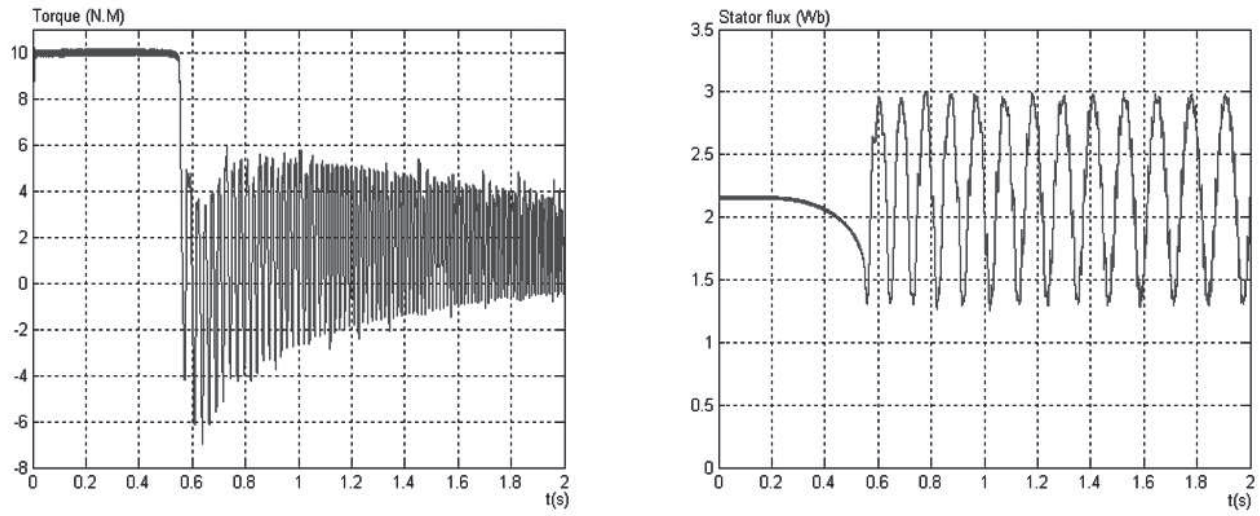

Figure 13. The resistance variation effect for conventional DTC control of DSSM.
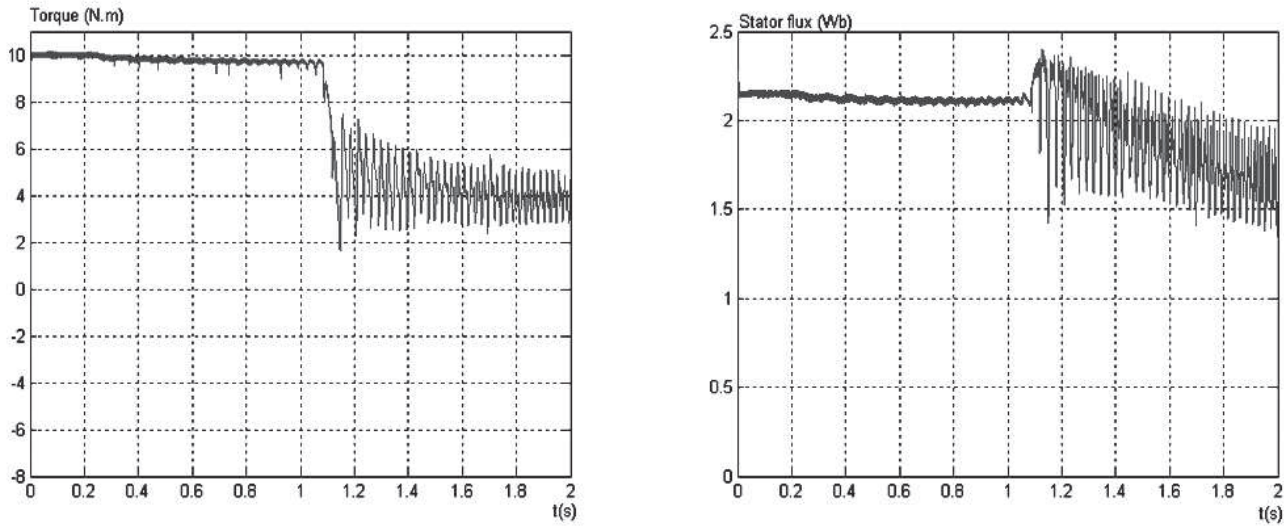

Figure 14. The resistance variation effect for backstepping/DTC control of DSSM.

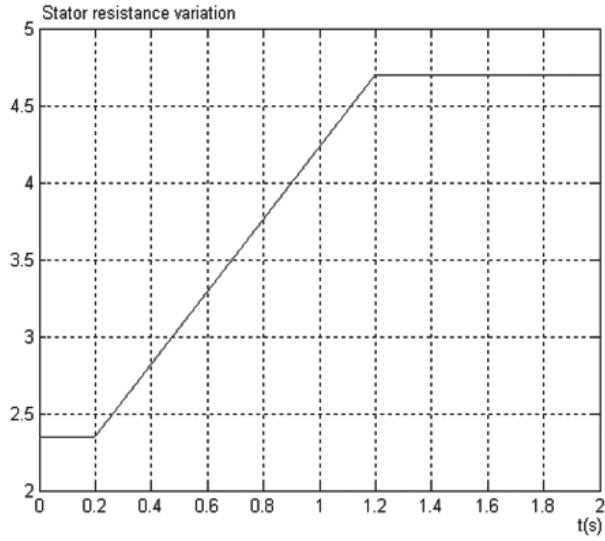

Figure 15. Actual stator resistance variation. 


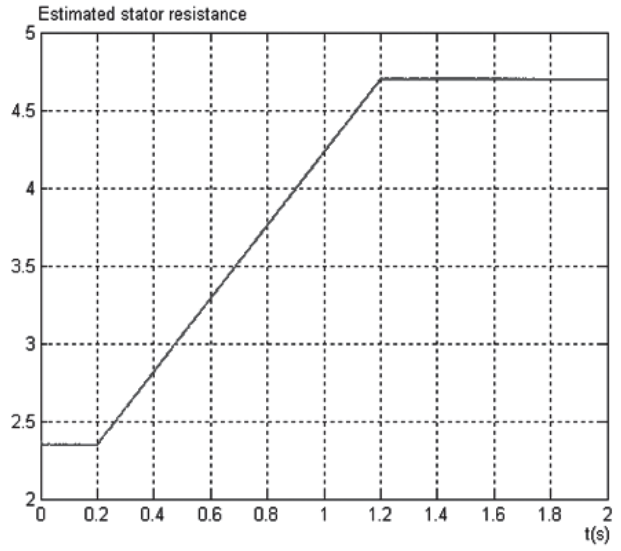

Figure 16. Estimated stator resistance.

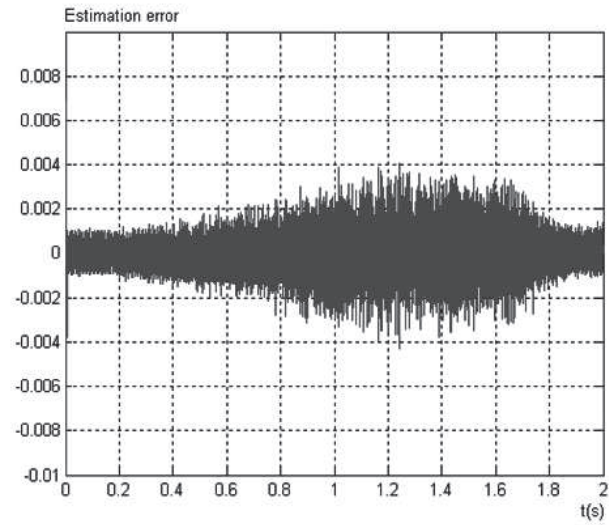

Figure 17. Estimation error.
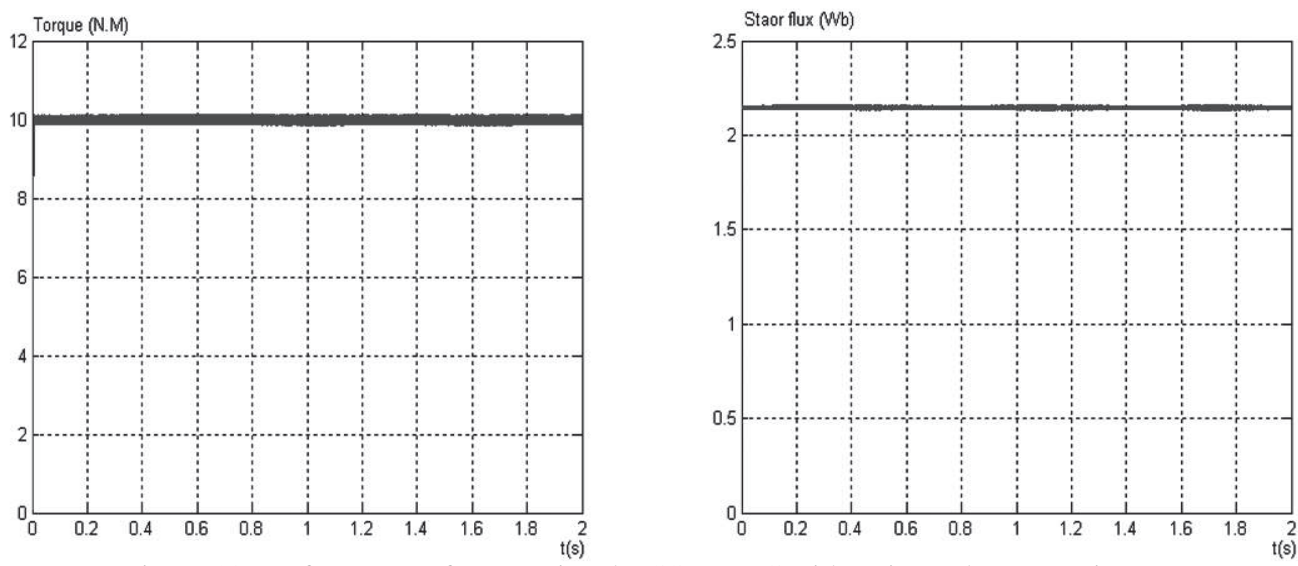

Figure 18. Performance of conventional DSSM DTC with estimated stator resistance. 

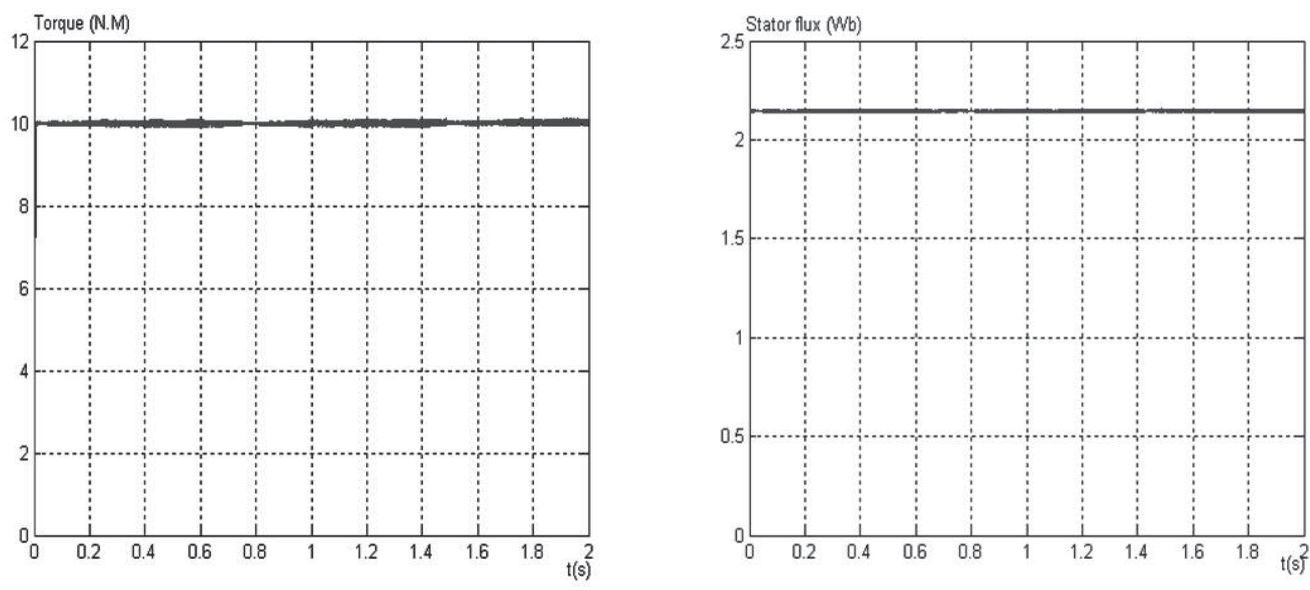

Figure 19. Performance of backstepping/DTC control of DSSM with estimated stator resistance.

\section{Appendix 1: List of principal symbols}

$i_{a 1}, i_{a 1}, i_{a 1}:$ stator current a, b, c phase of first winding

$i_{a 2}, i_{a 2}, i_{a 2}:$ stator current a, $\mathrm{b}, \mathrm{c}$ phase of second winding

$i_{\alpha}, i \beta \quad:$ stator current $\alpha-\beta$ axis

$i_{x}, i_{y} \quad:$ stator current $\mathrm{x}$-y axis

$i_{s} \quad:$ stator current vector

$v_{a 1}, v_{b 1}, v_{c 1}$ : simple voltage of stator three phase first winding

$v_{a 2}, v_{b 2}, v_{c 2}$ : simple voltage of stator three phase second winding

$v_{s} \quad:$ stator voltage vector

$v_{d}, v_{q} \quad:$ stator voltages $\mathrm{d}-\mathrm{q}$ axis

$v_{\alpha}, v_{\beta} \quad:$ stator voltages $\alpha-\beta$ axis

$v_{x}, v_{y} \quad:$ stator voltages $\mathrm{x}-\mathrm{y}$ axis

$L_{d}, L_{q} \quad: \quad \mathrm{d}-\mathrm{q}$ inductances

$\left[L_{s s}\right] \quad: \quad$ stator inductance matrix

$\left[M_{s r}\right] \quad: \quad$ stator-rotor mutual inductance matrix

$\left[R_{S}\right] \quad: \operatorname{diag}\left(R_{S} R_{S} R_{S} R_{S} R_{S} R_{S}\right)$

$R_{S} \quad:$ stator resistance

$R_{f} \quad:$ rotor resistance

$T_{e}, T_{e}^{*} \quad: \quad$ electromagnetic torque, reference torque

$T_{r} \quad:$ load torque

$\phi_{s}, \phi_{s}^{*} \quad:$ stator flux vector, reference flux vector

$\phi_{d}, \phi_{q} \quad:$ stator flux d-q axis

$\phi_{\alpha}, \phi_{\beta} \quad$ : stator flux $\alpha-\beta$ axis

$\phi_{x}, \phi_{y} \quad$ : stator flux x-y axis

$w$

: rotating speed of rotor flux linkage 


$\begin{array}{ll}w_{s} & : \text { rotating speed of stator flux linkage } \\ P h i & : \text { output of the flux hysteresis comparator } \\ \tau & : \text { output of the torque hysteresis comparator } \\ \delta & : \text { angle between rotor and stator flux linkage } \\ \theta_{r}, \theta_{s} & : \text { angle of rotor flux linkage, angle of stator flux linkage } \\ \Theta_{i} & : \text { the region numbers for the stator linkage positions } \\ E_{T}, E_{\phi} & : \text { torque error, flux error. } \\ J & : \text { moment of inertia } \\ f_{r} & : \text { friction coefficient } \\ P & : \text { number of pole pairs. }\end{array}$

\section{Appendix 2: DSSM parameters}

$P_{n}=5[\mathrm{~kW}]$

$U_{c}=232[\mathrm{~V}]$

$i_{f}=1[\mathrm{~A}]$

$R s=2.35 \Omega$

$R f=30.3 \Omega$

$L d=0.3811[\mathrm{H}]$

$L f=15[\mathrm{H}]$

$M d=2.146[\mathrm{H}]$

$J=0.05\left[\mathrm{Nms}^{2} / \mathrm{rd}\right]$

$f r=0.001[\mathrm{Nms} / \mathrm{rd}]$

$P=1$.

\section{References}

[1] L. WERREN: Synchronous machine with 2 three phase winding, spatially displaced by 30 'EL. Commutation reactance and model for converter-performance simulation. ICEM, Lausanne (Switzerland), 2 (1984), 781-784.

[2] N. Moubayed, F. Meibody-Tabar, B. Davat: Alimentation par deux onduleurs de tension d'une machine synchrone double étoile. Revue Internationle de Génie Electrique (RIGE), 1(4), (1998), 457-470, (in French).

[3] P.C. SEN: Electric motor drives and control - past present and future. IEEE Trans. on Industrial Electronics, 37(6), (1990), 562-575.

[4] Z. Chen and A.C. Williamson: Simulation study of a double three phase electric machine. Proc. Int. Conf. on Electric Ship, Istanbul, Turkey, (1998), 215-220. 
[5] D. Hadiouche, H. RaziK and A. Rezzoug: Modeling on double star induction motor for space vector PWM control. ICEM 2000, Finland, 1 (2000), 392-396.

[6] L. Nezli, M.O. Mahmoudi, M.S. Boucherit and M.Djemai: On vector control of double star synchronous machine with current fed inverters. The Mediterranean J. of Measurement and Control, 1(3), (2005).

[7] F.TERRIEN: Commande d'une machine synchrone double étoile, alimentée par deux onduleurs MLI. Thèse de doctorat de l'université de Nantes, 2000, (in French).

[8] M. Merabtene: Modelisation dynamique et commande d'une machine synchrone double étoile, alimentée par des onduleurs MLI fonctionnement en mode normal et dégrade. Thèse de doctorat de l'université de Nantes, 2005, (in French).

[9] R. Bojoi, F. Farina, G. Griva, F. Profumo, A. Tenconi: Direct torque control for dual-three phase induction motor drives. IEEE Trans. on Industry Applications, 41(6), (2005), 1627-1636.

[10] C. LAscu, I. BoldeA and F.BlaAbJERG: A modified direct torque control for induction motor sensorless drive. IEEE Trans. on Industry Applications, 36(1), (2000), 122-130.

[11] L. TONG, L. Zong and M.F. RAHMAN: Modeling and experimental approach of a novel direct torque control scheme for interior permanent magnet synchronous machine drive. Proc.IEEE IECON'02, 1 Seville, Spain, (2002), 235-240.

[12] J.ZHOU and Y.WANG: Adaptative backstepping speed controller design for permanent magnet synchronous motor. IEE Pro.-Electr. Power Appl., 149(2), (2002).

[13] M.F.Benkhoris, M.Merabtene, F.Meibody-Tabar, B.Davat, E.Semail: Approches de modélisation de la machine synchrone double étoile alimente par des onduleurs de tension en vue de la commande. RIGE, 6(5-6), (2003), 579-608, (in French).

[14] Y. ZHAO and T.A. LIPO: Space vector PMW control of dual three-phase induction machine using vector space decomposition. IEEE Trans. on Industry Applications, 31(5), (1995), 1100-1109.

[15] L. Zong, M.F. Rahman, W.Y. Hu and K.W. LiM: A direct torque controller for permanent magnet synchronous motor drives. IEEE Trans. on Energy Conversion, 14(3), (1999).

[16] L. Zong , M.F. Rahman, W.Y. Hu and K.W. Lim: Analysis of direct torque control in permanent magnet synchronous motor drives. IEEE Trans. Power Electronics, 12(3), (1997), 528-536. 
[17] G.S. BUJA and M.P. KAZMIERKOWSKI: Direct torque control of PWM inverterfed AC motors-a survey. IEEE Trans. on Industrial Electronics, 51(4), (2004), 744757.

[18] N.MADANI: Commande a structure variable d'une machine asynchrone double étoile alimentée par deux onduleurs MLI. Thèse de doctorat de l'université de Nantes, 2004, (in French). 